\title{
Determinants of efficiency growth of county-level public hospitals-evidence from Chongqing, China
}

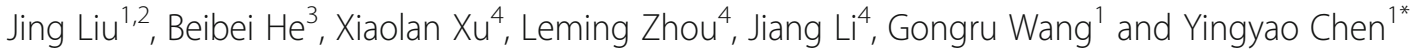

\begin{abstract}
Background: The reform of county-level public hospitals is a breakthrough in the new era of healthcare reform in China and has attracted considerable attention since 2012. Continuous and efficient operations of hospital are primary concerns of this reform. To ensure the effectiveness of county-based intervention reform measures in Chongqing, it is significant to understand how hospital and county characteristics are associated with county-level public hospital efficiency due to significant development differences between counties. This study identifies the trajectory of hospital efficiency over time and determinants. It will also provide preliminary references for advancing reform.

Methods: This study employs data from the Chongqing Regional Health Information Platform, Chongqing Health and Family Planning Statistical Yearbook, and Chongqing Statistical Yearbook for 2012-2016. A three-level growth model is used to estimate the efficiency growth trajectories within the contexts of hospitals and counties.

Results: The intra-hospital level factors that affect the initial efficiency include government financial assistance, daily charge per bed, total assets turnover, number of hospital healthcare technicians, and medical costs per 100-yuan medical income. Inter-hospital variance is explained by hospital type. Inter-county level factors affecting the growth rate include the number of healthcare technicians per 1000 people and population density of the county. The interaction effect of the number of hospital healthcare technicians, hospital type, and number of healthcare technicians per 1000 people on hospital efficiency growth is significant.

Conclusions: This study identifies determinants that contribute to efficiency changes in public county-hospitals over time by using a three-level growth model. The differences in efficiency are associated with intra-hospital, interhospital, and inter-county characteristics in Chongqing, which provides useful insight into government decisionmaking and the progress of reform. The stability and reasonable increase in the number of healthcare technicians in a county are the key factors that improve the efficiency. Further reform should focus on maternal and child healthcare hospitals for increasing investment and implementing government compensation.
\end{abstract}

Keywords: County hospital efficiency, Three-level growth model, Longitudinal data, Chongqing

\footnotetext{
* Correspondence: yychen@shmu.edu.cn

${ }^{1}$ Key Lab of Health Technology Assessment, National Health Commission,

School of Public Health, Fudan University, Shanghai 200032, People's

Republic of China

Full list of author information is available at the end of the article
}

(c) The Author(s). 2019 Open Access This article is distributed under the terms of the Creative Commons Attribution 4.0 International License (http://creativecommons.org/licenses/by/4.0/), which permits unrestricted use, distribution, and reproduction in any medium, provided you give appropriate credit to the original author(s) and the source, provide a link to the Creative Commons license, and indicate if changes were made. The Creative Commons Public Domain Dedication waiver (http://creativecommons.org/publicdomain/zero/1.0/) applies to the data made available in this article, unless otherwise stated. 


\section{Background}

Hospitals are one of the main components of the health system and also an important driver of increased health care costs constituting the largest single component of health expenditure in many countries [1]. They now face the daunting challenge of providing safe, effective care in complex organizations strapped by heavy patient loads, limited staffing, and shrinking financial resources [2]. Although the ratio of health expenditures to gross domestic product (GDP) in China has increased from $3.15 \%$ in 1980 to $6.36 \%$ in 2017 [3], the government is still confronted with an endemic public deficit. Under these circumstances, the new comprehensive nationwide health care reforms have been initiated by the Chinese government since 2009 and have focused on efficiency, quality, patient-centered care, and payment reforms [1]. In June 2012, the State Council issued the "Opinions on the Comprehensive Reform of Public Hospitals at the County Level" and determined that "the reform of public hospitals should take county hospitals as the breakthrough point," thus directing the focus of the medical reform to county-level public hospitals.

County-level public hospitals play an important role in the urban and rural medical and health service system in China. There are three types in China-general hospitals (GHs), traditional Chinese medicine hospitals (TCMHs), and maternal and child healthcare hospitals (MCHHs). These serve more than 900 million people, accounting for more than $70 \%$ of county residents [4]. In comparison with community health service agencies, township hospitals, and other primary health institutions, countylevel hospitals' internal operation management, external policy environment, commitment to medical tasks, and structure of personnel resources are more complex and dynamic [5]. They have long confronted the challenges of poor medical equipment, outdated technology, and weak scientific research. The reform of county-level public hospitals is targeted at the supply-side to form a more scientific and regulated management system, and mechanisms for governance, compensation, and monitoring, and to improve internal management to upgrade operating performance for safe, high quality, cost-effective, efficient, and better services [1]. Optimizing county health resource allocation and continuous and efficient operations are important considerations of the reform [6].

Therefore, it is significant to understand the relative efficiency in healthcare resource utilization for the county so that the National Health Commission of the People's Republic of China (NHCPRC) can develop targeted policy decision-making. Efficiency mainly examines the relationship between input and output. It is used to measure the extent to which resources are used effectively under given input conditions of an organization. Pareto efficiency is optimal under fully competitive market conditions and makes the most of the available resources. However, for public hospitals, in many cases, that do not have total competition in the marketplace, alternative strategies must be devised for improving efficiency in resource use [7]. Moreover, county-level public hospitals seeking to improve efficiency and maximize health outcomes must first address the question of how to identify determinants [8].

This study identifies determinants of the efficiency of county-level hospitals in Chongqing, China. Chongqing is located in the western part of China and has a population of 30 million. It is spread over a vast area, of which mountains account for $76 \%$ [9]. There are significant differences in the development of counties. In 2007, the State Development and Reform Commission officially established Chongqing as a pilot area for the overall development and reform of counties, along with Chengdu. Chongqing is required to comprehensively promote the reform of various aspects, in accordance with the requirements of the reform experiment, for the comprehensive planning of counties. In recent years, Chongqing's government has taken various effective measures to promote the balanced development of counties and gradually narrow the gap, with the integration of county health as the focus. This requires equity of basic public health and the homogenization of basic medical services. However, due to significant differences between counties, the balanced development of county health services still faces great challenges. To continue developing reform measures that reduce the gap in county health services, it is important to understand whether there is a difference in the efficiency between county-level hospitals in different hospitals and counties, and what determinants influence them. Therefore, we propose the following research questions: How efficiency are county public hospitals? Has the efficiency improved since the new healthcare reform was initiated in 2012? In what ways have efficiency growth trajectories changed over time? Do these trajectories vary significantly across hospitals and counties? If so, are there any hospital or county characteristics associated with this variation? The study assumptions are as follows:hypothesis 1: there is a difference in hospital efficiency between hospitals and counties; hypothesis 2: county characteristics have an impact on efficiency; hypothesis 3: hospital characteristics have an impact on efficiency; hypothesis 4: intrahospital characteristics have an impact on efficiency; hypothesis 5: intra-hospital, hospital, and county characteristics will affect the efficiency growth and can adjust the relationship between time and it. To answer the above questions and verify hypotheses, the present study examined the relationships among efficiency, intra-hospital, inter-hospital, and inter-county characteristics.

\section{Literature review}

Hospital efficiency analysis is an important issue within the field of health economics, and while there is abundant 
literature on this subject $[6,10-30]$, only a handful of studies focus on identifying the determinants of hospital efficiency [16-22]. Moreover, there is little research on which hospital and county characteristics are associated with efficiency changes. A review of the literature on hospital efficiency identifies two contemporary approaches to measure hospital efficiency: parametric and non-parametric approaches [31]. Efficiency measurement methods have been continuously innovated, such as stochastic frontier analysis, data envelopment analysis (DEA), and the bootstrap method. The DEA method has received increasing attention and is a valuable efficiency measurement and benchmarking tool for most organizations, especially in the healthcare sector [8]. This methodology not only expands the applications of efficiency evaluation, but also increases the accuracy of efficiency measurements and provides a new perspective for the study of hospital efficiency. Simultaneously, the research objective has evolved from purely the measurement of efficiency to the discussion of factors affecting efficiency to provide a direction for efficiency improvement. Although some studies use ordinary least squares, Tobit analysis has been the most popular analytical method, wherein the output-based efficiency score or reciprocal of the input-based efficiency score is regressed on variables posited to affect efficiency [32,33].

The relationships among hospital efficiency and hospital and regional characteristics are often analyzed separately $[24,27,34]$. Prior literature suggests that hospital size and average length of stay are negatively associated with efficiency, whereas occupancy rate, bed-to-nurse ratio, and nurse-to-physician ratio are positively associated with efficiency [6]. Small and rural hospitals are slightly less efficient compared with large and urban hospitals, and teaching hospitals are substantially more efficient compared with non-teaching hospitals [22]. Although such research has attracted increasing attention from scholars, there remains a lack of formal academic studies examining the efficiency of healthcare delivery systems across states or counties. Hussey et al. [35] note that, between 1990 and 2008, only four studies examined the geographical differences in healthcare efficiency. To date, no study has been conducted on county-level public hospitals' efficiency change over time to identify variables that accurately predict change across states or counties. Moreover, analysis has been limited to cross-sectional models. Gearhart [36] hypothesized that cross-country healthcare efficiency rankings should not be the primary tool to drive reform and policy. For policy prescriptions based on efficiency rankings, one should look within a country by considering efficiency rankings among individual states or localities [36], because there is an objective correlation between individual states and localities. Ignoring the rankings will inevitably bias the analysis results. This highlights the potential for methodological improvement [37].
A multilevel growth model is an effective statistical model to solve the above contradiction with longitudinal data [38-40]. Over the past several decades, longitudinal designs for studying individuals' growth and change have slowly become popular in the area of psychological wellbeing (e.g., [41, 42]), although they are rarely used in studies on hospital efficiency. To ensure the effectiveness of county-based intervention reform measures in Chongqing, it is important to understand how hospital and county characteristics were associated with county-level public hospital efficiency. Three-level growth model was used to describe and demonstrate the importance of examining both hospital and county characteristics related to efficiency over time. Through the analysis of different hospital and county characteristics, the effects of these characteristics on the initial efficiency and efficiency growth rate are revealed, and the interaction effects are tested. The variability in efficiency trajectories between hospitals and counties was a unique perspective. The characteristics of counties and hospitals were examined to determine if they explain variability across the average growth trajectories of counties and hospitals.

This study contributes to the current knowledge base by filling the abovementioned gap in literature using the Chongqing case, and presents an innovation by introducing the multilevel growth model into the area of hospital efficiency studies. It will also provide important references for policymakers and hospital managers.

\section{Methods \\ Materials and methods}

To study the trajectory of hospital efficiency growth and the effects of hospital and county characteristics on efficiency, a three-level growth model was used. All analyses were conducted using the Mplus 8.0 software and the maximum likelihood robust estimator. In a three-level growth model (see Fig. 1), ${ }^{1}$ Level-1(Intra-hospital level) is a repeated observation at different times in the same hospital, observing the growth trajectory of each hospital over time; Level-2 (Inter-hospital level) is an interhospital observation that determines the heterogeneity of individual changes and how different hospital characteristics influence changes in efficiency; Level 3 (Intercounties level) is a group variable that determines the heterogeneity of changes between counties [44].

A three-level growth model does not need to assume individual independence and can correct the bias of parameter standard error estimation caused by the nonindependence of observation data. The effects of lessand highly independent variables on outcomes can be

\footnotetext{
${ }^{1}$ In this figure, horizontal arrows represent the role of a horizontal variable, and diagonal arrows represent the interaction between horizontal variables.
} 


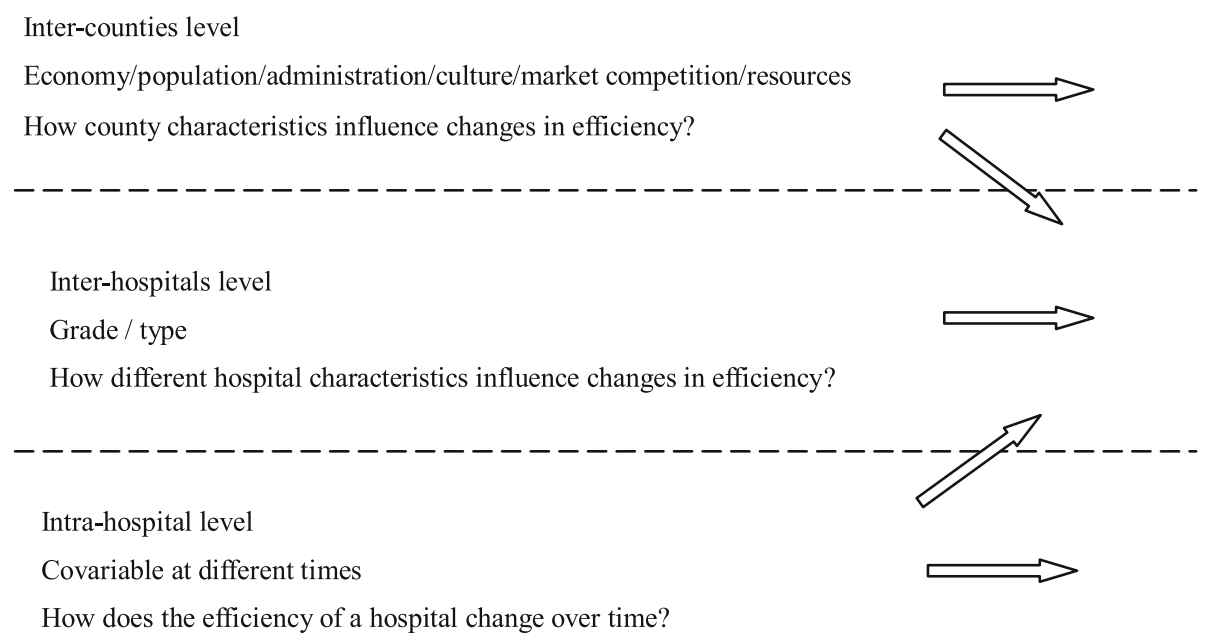

Fig. 1 Defining variables in a three-level growth model [43]

analyzed simultaneously. Random slope and crosshorizontal interactions can also be analyzed. The initial mean levels of the dependent variable and each explanatory variable can be obtained with parameter estimation results of the fixed component.

After considering the effect of different interpretation variables on the development differences between hospitals, three-level growth model use the difference between the interception and slope to explain the degree of change in the interpretation of the differences through parameter estimation of the random component [45]. Compared with traditional statistical methods, it is more flexible and has advantages in dealing with repeated measurement data.

\section{Sample and data sources}

There are 38 counties in Chongqing totally. We implemented a purposive sampling design to obtain a representative sample of county hospitals throughout Chongqing, and to focus on 24 counties on the premise of balancing the geographical, economic, and service population characteristics, as well as hospital operations, according to the recommendation by the Chongqing Health Commission. The sample size was determined by data availability and the DEA method requires a complete set of input and output variables for study. ${ }^{2}$ Efficiency, Intra-hospital changes, hospital characteristics, and county characteristics were measured at five points from 2012 to 2016, forming a repeated measurement of annual data for five years. Relevant operational data were taken from the Chongqing Regional Health Information Platform. Information on county characteristics was supplemented from the Chongqing Health and Family Planning Statistical Yearbook and Chongqing

\footnotetext{
${ }^{2}$ The minimum sample capacity of the DEA model is $2^{*} \mathrm{~N}^{*} \mathrm{M}$, where $\mathrm{N}$, $\mathrm{M}$ represent the number of inputs and output indicators, respectively.
}

Statistical Yearbook (2012-2016). Finally, 360 observations were obtained, and we had a multilevel longitudinal data set. No patient information was included in the study, so an ethics statement was not needed. An obvious feature of the above data was the multilevel nesting structure: observation time variables were nested in hospitals, and hospitals were nested in counties. The results in a sample of 72 hospitals were nested within 24 counties.

\section{Variables construction}

Efficiency requires a production process [or unit] to maximize output for a given level of inputs [22]. Under the limited health resources in counties, the total market competition makes the resource utilization optimal and the efficiency increases gradually. An ability to operate efficiently often depends on the operational conditions and practices, such as the external operational environment in which production occurs, internal characteristics of firms, such as the type and vintage of technology, and managerial practices [46]. Therefore, the above measures of such contextual factors provide a better understanding of efficiency differences and identify the key efficiency determinants across hospitals. The factors of the geopolitical setting, economy, population structure and state of health, health resources, medical market competition, and demand for health services, as discussed in previous literature, pose challenges to healthcare delivery and access. Therefore, we hypothesize that these factors influence the efficiency of hospitals, and, thus, are included in our analysis.

The level-1 variables are measured over five time periods to determine how the efficiency of a hospital changed over five years. Following the literature review [47-49], level-1 variables include: financial assistance, medical business area, actual number of beds 
available, number of hospital healthcare technicians, total fixed assets, daily charge per bed, medical costs per 100-yuan medical income, ${ }^{3}$ total assets turnover, ratio of revenue and expenditure, and asset-liability ratio, on behalf of the hospital's internal operation management. Level-2 variables identified how different characteristics of hospitals influence changes in hospital efficiency. These variables include hospital grade (unrated, middle second-class, upper secondclass, middle first-class, and upper first-class hospitals) and type (GHs, TCMHs, and MCHHs). Level-3 variables identified how county characteristics influence changes in hospital efficiency. These variables include: per capita GDP, number of healthcare technicians per 1000 people (reflecting regional health resources), population density (reflecting population characteristics), density of medical institutions (reflecting medical market competition), and urbanization rate (reflecting counties' economy, administration, and culture) [50, 51]. Efficiency is hospital technical efficiency scores and came from the input-oriented BCC-CCR DEA model. In this model, the selection of input and output variables was guided by previous empirical studies $[49,52-55]$ and systematic clustering analysis, depending on the availability of data in the Chongqing Regional Health Information Platform. Four input indicators and four output indicators were selected. The statistical characteristics of the input-output data are shown in Table 1 . Remaining measurement variables of various levels of the multilevel growth model are shown in Table 2.

\section{Model development}

The model is developed in four main steps. To verify the existence of hierarchy in the data, we first establish an empty Eq. 1 with uninterpreted variables:

$$
\begin{aligned}
& \text { Level-1: } Y_{t i j}=\pi_{0 i j}+e_{t i j} \\
& \text { Level-2: } \pi_{0 i j}=\beta_{00 j}+r_{0 i j} \\
& \text { Level-3: } \beta_{00 j}=\gamma_{000}+u_{00 j}
\end{aligned}
$$

Here, $Y$ is the efficiency score of hospitals, $t=0,1,2,3 \ldots$, represents the year; $i=1,2,3 \ldots$ indicates the hospital; $j=$ $1,2,3 \ldots$ indicates the county; $\gamma_{0 o o}$ represents the average of total efficiency, and $e_{t i j}, r_{0 i j}$, and $u_{o o j}$ represent random variations of levels 1,2 , and 3 , respectively. $\pi_{0 i j}$ represents the five-year average efficiency of the $i$ hospitals in the $j$ counties, $\beta_{0 o j}$ represents the average efficiency of the $j$ counties.

To test for a significant increase in efficiency and variance in levels 2 and 3 and to determine the rate of this

\footnotetext{
${ }^{3}$ In China, the medical costs per 100-yuan medical income is measured as follows: (medical business cost + administrative cost) / (medical income $\left.{ }^{*} 100\right)$ and is used to measure hospital cost management.
}

\begin{tabular}{|c|c|c|c|c|}
\hline Indicators & Min. & Max. & Mean & Std. Dev. \\
\hline \multicolumn{5}{|l|}{ Input } \\
\hline Physical area of the hospital & 806 & 136,000 & $21,088.68$ & $23,472.26$ \\
\hline Actual number of open beds & 15 & 1470 & 342.66 & 307.36 \\
\hline Total fixed assets & 1264 & 635,559 & $56,597.5$ & $84,562.53$ \\
\hline $\begin{array}{l}\text { Number of healthcare } \\
\text { technicians }\end{array}$ & 18 & 1403 & 343.18 & 295.22 \\
\hline \multicolumn{5}{|l|}{ Output } \\
\hline Total income & 2490 & 942,523 & $139,816.37$ & $144,548.81$ \\
\hline $\begin{array}{l}\text { Number of hospital bed } \\
\text { rotations }\end{array}$ & 16.43 & 137.41 & 50.82 & 19.9 \\
\hline $\begin{array}{l}\text { Number of outpatient } \\
\text { and emergency visits }\end{array}$ & 9372 & 847,318 & $212,314.14$ & $172,899.31$ \\
\hline $\begin{array}{l}\text { Number of discharged } \\
\text { patients }\end{array}$ & 93 & 66,737 & $13,425.69$ & $12,824.62$ \\
\hline
\end{tabular}

Table 1 Statistical characteristics of input-output indicators of DEA model

growth change, we established an unconditional growth model (random coefficient model, Eqs. 2 and 3). Level 1 includes only $T$ (time variables), and levels 2 and 3 did not include any explanatory variables; we set the slope of the time variables to be random. Models of linear growth (Eq. 2) and nonlinear growth (Eq. 3) were established to investigate the possible growth curve of efficiency.

$$
\begin{array}{ll}
\text { Level-1: } & Y_{t i j}=\pi_{0 i j}+\pi_{1 i j}\left(T_{t i j}\right)+e_{t i j} \\
\text { Level-2 : } & \pi_{0 i j}=\beta_{00 j}+r_{0 i j} \\
& \pi_{1 i j}=\beta_{10 j}+r_{1 i j} \\
\text { Level-3: } & \beta_{00 j}=\gamma_{000}+u_{00 j} \\
& \beta_{10 j}=\gamma_{100}+u_{10 j}
\end{array}
$$

Here, $r_{O i j}$ is an interceptor residual in Level $2, r_{1 i j}$ is a slope residue residual in Level $2 ; u_{00 j}$ is an interceptor residual in Level $3, u_{10 j}$ is a slope residue residual in Level $3 . \beta_{10 j}$ is the average linear growth rate of efficiency in the $j$ hospitals, and $\gamma_{100}$ is the overall average linear growth rate of efficiency. The remaining parameters have the same meaning as Eq. 1.

$$
\begin{array}{ll}
\text { Level-1 : } & Y_{t i j}=\pi_{0 i j}+\pi_{1 i j}\left(T_{t i j}\right)+\pi_{2 i j}\left(T_{t i j}^{2}\right)+e_{t i j} \\
\text { Level-2: } & \pi_{0 i j}=\beta_{00 j}+r_{0 i j} \\
& \pi_{1 i j}=\beta_{10 j}+r_{1 i j} \\
& \pi_{2 i j}=\beta_{20 j}+r_{2 i j} \\
\text { Level-3: } & \beta_{00 j}=\gamma_{000}+u_{00 j} \\
& \beta_{10 j}=\gamma_{100}+u_{10 j} \\
& \beta_{20 j}=\gamma_{200}+u_{20 j}
\end{array}
$$

Here, $\beta_{20 j}$ is the average nonlinear growth rate of efficiency in $j$ hospital, $\gamma_{200}$ is the average nonlinear growth 
Table 2 Measurement variables and interpretations at all levels

\begin{tabular}{|c|c|c|}
\hline Variable code & Variable name & Description and measure of the variable \\
\hline y & Efficiency & Hospital technical efficiency score \\
\hline Level-1 & Intra-hospital changes & \\
\hline t & Time & $\begin{array}{l}\text { Years } 2012-2016 \text { expressed as } 0-4, \\
\text { respectively }\end{array}$ \\
\hline FP & Government financial assistance & Annual financial input (unit: 10000 yuan) \\
\hline A2 & Physical area of the hospital & Physical area of the hospital (unit: square meter) \\
\hline A3 & Actual number of open beds & Actual number of open beds per year (unit: bed) \\
\hline A6 & Number of healthcare technicians & $\begin{array}{l}\text { Annual number of hospital healthcare technical } \\
\text { personnel (unit: person) }\end{array}$ \\
\hline A11 & Total fixed assets & Total annual fixed assets (unit: 10000 yuan) \\
\hline V1 & $\begin{array}{l}\text { Daily charge per bed } \\
\text { (Cost of every bed-day in } \\
\text { hospital: yuan/ bed-day) }\end{array}$ & $\begin{array}{l}\text { Hospitalization income (including medical and pharmaceutical) / } \\
\text { actual occupancy bed-days }\end{array}$ \\
\hline V7 & $\begin{array}{l}\text { Medical costs per 100-yuan } \\
\text { medical income }\end{array}$ & (Medical business cost + management cost) / (medical income * 100) \\
\hline V8 & Total assets turnover & (Medical income + other income) / total assets \\
\hline V9 & Ratio of revenue and expenditure & $\begin{array}{l}\text { Balance of revenue and expenditure / (medical income }+ \text { [basic income, } \\
\text { financial assistance, and other income }] \text { ) }{ }^{*} 100 \%\end{array}$ \\
\hline V10 & Asset-liability ratio & Total liabilities / total assets * 100\% \\
\hline Level-2 & Inter-hospital differences & \\
\hline GHP & Hospital grade & $\begin{array}{l}\text { Numbers } 0-4 \text { represent unrated, middle second-class, upper second-class, } \\
\text { middle first-class, and upper first-class hospitals, respectively }\end{array}$ \\
\hline THP & Hospital category & $\begin{array}{l}\text { Taking general hospitals as the reference category, the two virtual variables } \\
\text { are transformed into maternal and child healthcare hospitals (FY) and } \\
\text { traditional Chinese medicine hospitals (ZY) }\end{array}$ \\
\hline Level-3 & Inter-county differences & \\
\hline GDP & $\begin{array}{l}\text { Per capita gross domestic } \\
\text { product (GDP) }\end{array}$ & $\begin{array}{l}\text { GDP / county population; measures a region's economic development } \\
\text { and standard of living }\end{array}$ \\
\hline D1 & $\begin{array}{l}\text { Number of healthcare technicians } \\
\text { per } 1000 \text { people (person) }\end{array}$ & $\begin{array}{l}\text { Total healthcare technician population / (county population * } 1000 \text { ); } \\
\text { measures the level of human resource investment and equity of the } \\
\text { distribution of medical and health services }\end{array}$ \\
\hline DP & Population density & Total population / county area; used to measure county health service needs \\
\hline $\mathrm{HP}$ & Density of medical institutions & $\begin{array}{l}\text { Total number of medical institutions in the area / county area; } \\
\text { measures } \\
\text { county medical institutions' competition }\end{array}$ \\
\hline$C Z$ & Urbanization rate & $\begin{array}{l}\text { Urban population / permanent population; used to measure social and } \\
\text { cultural development of a county }\end{array}$ \\
\hline
\end{tabular}

Source: Chongqing Health Information Center, Chongqing Health and Family Planning Statistical Yearbook, and Chongqing Statistical Yearbook

rate of efficiency, and $u_{20 j}$ is the slope residue residual in Level-3. The remaining parameters have the same meaning as Eq. 2.

Based on Eq. 2 and Eq. 3, we include the explanatory variables at level 3 (Eq. 4) and level 2 (Eq. 5), and level 1 remained unchanged. To prevent multicollinearity between the interaction and original variable, explanatory variables at level 3 were grand-mean center processed. All variables at level 2 were categorical or hierarchical variables without centralization. Based on Eq. 5, the explanatory variables at level 1 were treated as group- mean centered and included to create Eq. 6. In Eqs. 4, 5 and $6, \gamma_{o o p}(p=1,2,3 \ldots 5)$ is the slope of the influence of the level 3 interpretation variable on the initial efficiency score; $\gamma_{10 p}(p=1,2,3 \ldots 5)$ is the slope of the influence of the level 3 interpretation variables on the growth rate of efficiency; $\beta_{o p j}(p=1,2,3,4)$ is the slope of the level 2 interpretation variable on the initial efficiency score; and $\beta_{1 p j}(p=1,2,3,4)$ is the slope of the level 2 interpretation variable on the efficiency growth rate. The remaining parameters have the same meaning as previous models. 
Level-1 : $\quad Y_{t i j}=\pi_{0 i j}+\pi_{1 i j}\left(T_{t i j}\right)+e_{t i j}$

Level-2 : $\quad \pi_{0 i j}=\beta_{00 j}+r_{0 i j}$

$$
\pi_{1 i j}=\beta_{10 j}+r_{1 i j}
$$

Level-3 : $\quad \beta_{00 j}=\gamma_{000}+\gamma_{001}(G D P)+\gamma_{002}(D 1)$

$$
\begin{aligned}
& +\gamma_{003}(D P)+\gamma_{004}(H P)+\gamma_{005}(C Z) \\
& +u_{00 j} \beta_{10 j}=\gamma_{100}+\gamma_{101}(G D P) \\
& +\gamma_{102}(D 1)+\gamma_{103}(D P)+\gamma_{104}(H P) \\
& +\gamma_{105}(C Z)+u_{10 j}
\end{aligned}
$$

Level-1: $\quad Y_{t i j}=\pi_{0 i j}+\pi_{1 i j}\left(T_{t i j}\right)+e_{t i j}$

Level-2 : $\quad \pi_{0 i j}=\beta_{00 j}+\beta_{01 j}(G H P)+\beta_{02 j}($ IHP $)$

$$
\begin{aligned}
& +\beta_{03 j}(Z Y)+\beta_{04 j}(F Y)+r_{0 i j} \pi_{1 i j} \\
& =\beta_{10 j}+\beta_{11 j}(G H P)+\beta_{12 j}(I H P)
\end{aligned}
$$

Level-3: $\quad \beta_{00 j}=\gamma_{000}+\gamma_{001}(G D P)+\gamma_{002}(D 1)$

$$
\begin{aligned}
& +\beta_{13 j}(Z Y)+\beta_{14 j}(F Y)+r_{1 i j} \\
& +\gamma_{003}(D P)+\gamma_{004}(H P)+\gamma_{005}(C Z) \\
& +u_{00 j} \\
\beta_{10 j}= & \gamma_{100}+\gamma_{101}(G D P)+\gamma_{102}(D 1) \\
& +\gamma_{103}(D P)+\gamma_{104}(H P)+\gamma_{105}(C Z) \\
& +u_{10 j}
\end{aligned}
$$

$$
\begin{aligned}
& \text { Level-1 : } \quad Y_{t i j}=\pi_{0 i j}+\pi_{1 i j}\left(T_{t i j}\right)+\pi_{2 i j}\left(F P_{t i j}\right) \\
& +\pi_{3 i j}\left(A 2_{t i j}\right)+\pi_{4 i j}\left(A 3_{t i j}\right)+\pi_{5 i j}\left(A 6_{t i j}\right) \\
& +\pi_{6 i j}\left(A 11_{t i j}\right)+\pi_{7 i j}\left(V 1_{t i j}\right)+\pi_{8 i j}\left(V 7_{t i j}\right) \\
& +\pi_{9 i j}\left(V 8_{t i j}\right)+\pi_{10 i j}\left(V 9_{t i j}\right) \\
& \text { Level-2: } \quad \pi_{0 i j}=\beta_{00 j}+\beta_{01 j}(G H P)+\beta_{02 j}(I H P)+\beta_{03 j}(Z Y) \\
& +\pi_{11 i j}\left(V 10_{t i j}\right)+e_{t i j} \\
& +\beta_{04 j}(F Y)+r_{0 i j} \\
& \pi_{1 i j}=\beta_{10 j}+\beta_{11 j}(G H P)+\beta_{12 j}(I H P)+\beta_{13 j}(Z Y) \\
& +\beta_{14 j}(F Y)+r_{1 i j} \\
& \text { Level-3: } \quad \beta_{00 j}=\gamma_{000}+\gamma_{001}(G D P)+\gamma_{002}(D 1)+\gamma_{003}(D P) \\
& +\gamma_{004}(H P)+\gamma_{005}(C Z)+u_{00 j} \\
& \beta_{10 j}=\gamma_{100}+\gamma_{101}(G D P)+\gamma_{102}(D 1)+\gamma_{103}(D P) \\
& +\gamma_{104}(H P)+\gamma_{105}(C Z)+u_{10 j}
\end{aligned}
$$

To test the interaction effect between a single variable at level 1 and the time, the slope of each explanatory variable at level 1 is set separately as the cross-layer random slope. The results show that the random slope of all these variables is not significant at levels 2 and 3, and so we fix all their slopes. This study assumes that variables $F P, A 2, A 3, A 6$, and A11 affect the growth rate; that is, the relationship between time and efficiency. The interaction between these explanatory variables and time are included in the respective models, thus resulting in Eq. 7 (the full model).

$$
\begin{aligned}
& \text { Level-1 : } \quad Y_{t i j}=\pi_{0 i j}+\pi_{1 i j}\left(T_{t i j}\right)+\pi_{2 i j}\left(F P_{t i j}\right) \\
& +\pi_{3 i j}\left(A 2_{t i j}\right)+\pi_{4 i j}\left(A 3_{t i j}\right)+\pi_{5 i j}\left(A 6_{t i j}\right) \\
& +\pi_{6 i j}\left(A 11_{t i j}\right)+\pi_{7 i j}\left(V 1_{t i j}\right)+\pi_{8 i j}\left(V 7_{t i j}\right) \\
& +\pi_{9 i j}\left(V 8_{t i j}\right)+\pi_{10 i j}\left(V 9_{t i j}\right) \\
& +\pi_{11 i j}\left(V 10_{t i j}\right)+\pi_{12 i j}\left(T_{t i j} \times A 2_{t i j}\right) \\
& +\pi_{13 i j}\left(T_{t i j} \times A 3_{t i j}\right)+{ }_{14 i j}\left(T_{t i j} \times A 6_{t i j}\right) \\
& +\pi_{15 i j}\left(T_{t i j} \times A 11_{t i j}\right)+e_{t i j} \\
& \text { Level-2 }: \quad \pi_{0 i j}=\beta_{00 j}+\beta_{01 j}(G H P)+\beta_{02 j}(I H P)+\beta_{03 j}(Z Y) \\
& +\beta_{04 j}(F Y)+r_{0 i j} \\
& \pi_{1 i j}=\beta_{10 j}+\beta_{11 j}(G H P)+\beta_{12 j}(I H P)+\beta_{13 j}(Z Y) \\
& +\beta_{14 j}(F Y)+r_{1 i j} \\
& \pi_{p i j}=\beta_{p 0 j ;} \\
& \text { Level-3: } \quad \beta_{00 j}=\gamma_{000}+\gamma_{001}(G D P)+\gamma_{002}(D 1)+\gamma_{003}(D P) \\
& +\gamma_{004}(H P)+\gamma_{005}(C Z)+u_{00 j} \\
& \beta_{10 j}=\gamma_{100}+\gamma_{101}(G D P)+\gamma_{102}(D 1)+\gamma_{103}(D P) \\
& +\gamma_{104}(H P)+\gamma_{105}(C Z)+u_{10 j} \\
& \beta_{p 0 j}=\gamma_{p 00 ;}
\end{aligned}
$$

Among them, $\pi_{12 i j} 、 \pi_{13 i j} 、 \pi_{14 i j} 、 \pi_{15 i j}$ are the slope of the interaction items of $A 2, A 3, A 6$, and $A 11$ with the time variable $T$ on the initial efficiency. Other parameters have the same meaning as the preceding model.

\section{Results}

Descriptive results

Descriptive statistics were depicted for the hospitals' efficiency scores and other continuous variables across the five measurement points (Tables 3 and 4). As seen in Table 3, the mean efficiency score was 0.79 in 2012 and 0.85 in 2016, exhibiting a trend that was growing at an increasing rate in Chongqing. Due to lack of the national average efficiency scores, we did literature review and found the score in 2012 was lower than those scores in other provinces [56-59], the changes over time indicate a diversifying trend of efficiency over the years. 
Table 3 Descriptive statistics of continuous variables

\begin{tabular}{|c|c|c|c|c|c|}
\hline Variable name & Years & Min. & Max. & Mean & Std. Dev. \\
\hline \multirow[t]{6}{*}{ Efficiency score } & 2012-2016 & 0.42 & 1.00 & 0.83 & 0.16 \\
\hline & 2012 & 0.50 & 1.00 & 0.79 & 0.18 \\
\hline & 2013 & 0.47 & 1.00 & 0.83 & 0.16 \\
\hline & 2014 & 0.51 & 1.00 & 0.81 & 0.16 \\
\hline & 2015 & 0.55 & 1.00 & 0.86 & 0.13 \\
\hline & 2016 & 0.42 & 1.00 & 0.85 & 0.15 \\
\hline Government financial assistance & 2012-2016 & 0.00 & 0.82 & 0.19 & 0.17 \\
\hline Physical area of the hospital & & 806.00 & $136,000.00$ & $21,088.68$ & $23,472.26$ \\
\hline Actual number of open beds & & 15.00 & 1470.00 & 342.66 & 307.36 \\
\hline Number of healthcare technicians & & 18.00 & 1403.00 & 343.18 & 295.22 \\
\hline Total fixed assets & & 1264.00 & $635,559.00$ & $56,597.50$ & $84,562.53$ \\
\hline Daily charge per bed (Cost of every bed-day in hospital: yuan/bed-day) & & 0.30 & 2.89 & 0.83 & 0.28 \\
\hline Medical costs per 100-yuan medical income & & 0.0009 & 0.0247 & 0.0106 & 0.0022 \\
\hline Total assets turnover & & 0.09 & 6.06 & 1.20 & 0.70 \\
\hline Ratio of revenue and expenditure & & -3.686 & 98.018 & 22.45 & 16.37 \\
\hline Asset-liability ratio & & 0.00 & 102.03 & 44.95 & 25.21 \\
\hline Per capita gross domestic product (GDP) & & $12,969.47$ & $91,552.13$ & $37,720.33$ & $19,792.18$ \\
\hline Number of healthcare technicians per 1000 people (person) & & 1.70 & 17.70 & 4.42 & 2.73 \\
\hline Population density & & 0.01 & 0.40 & 0.07 & 0.10 \\
\hline Density of medical institutions & & 0.06 & 1.92 & 0.35 & 0.41 \\
\hline Urbanization rate & & 27.120 & 95.70 & 49.27 & 20.35 \\
\hline
\end{tabular}

Note: The efficiency score is technical efficiency derived from the result of the DEA model. DEAP 2.1 software was used

\section{Analytic results}

The results of Eq. 1 (Table 5) showed that the intraclass correlation coefficient (ICC) is $48.2 \%$ (ICC > 16\%), indicating that $48.2 \%$ of total variance in average efficiency existed at level 2. For level 3, 6\% $<\mathrm{ICC}<16 \%$ (ICC $=$ $8.1 \%$ ), which indicated that $8.1 \%$ of the total variance in average efficiency exists at level 3 [60]. Based on this, the preliminary judgment was that there are statistically significant variance at both levels 2 and 3 [61]. Because the multilevel growth model considers both the initial efficiency and the slope, we must combine the significant test results of the increasing slope of $Y$ in level 3 to judge the suitability of the three-level model.
The results of Eqs. 2 and 3 (Table 5) showed that the average growth rate of the linear growth model was significant $(\beta=0.016)$. There was a significant, negative correlation between the linear growth rate and initial efficiency $(r=-0.003)$, indicating that the lower the initial efficiency score, the higher the growth rate. However, the primary (linear) growth rate of the nonlinear growth model was significant $(\beta=0.028)$ and the secondary (nonlinear) growth rate was not significant $(\beta=-$ $0.003)$, suggesting that linear growth is maintained. In addition, the growth variance of the linear growth model was significant at levels 2 and 3, but variance of the primary and secondary growth rates in the nonlinear

Table 4 Level 2 descriptive statistics

\begin{tabular}{|c|c|c|c|c|c|}
\hline \multicolumn{3}{|l|}{ GHP } & \multicolumn{3}{|l|}{ THP } \\
\hline Groups & $\mathrm{N}$ & Percentage (\%) & Groups & $\mathrm{N}$ & Percentage (\%) \\
\hline Upper first-class hospital & 30 & 8.3 & General hospitals & 120 & 33.3 \\
\hline Upper second-class hospital & 230 & 63.9 & Traditional Chinese medicine hospitals & 120 & 33.3 \\
\hline Middle second-class hospital & 65 & 18.1 & Maternal and child healthcare hospitals & 120 & 33.3 \\
\hline No grade & 35 & 9.7 & & & \\
\hline Total & 360 & 100.0 & & 360 & 100.0 \\
\hline
\end{tabular}

Note: GHP hospital grade, THP hospital category 
Table 5 Results of all models

\begin{tabular}{|c|c|c|c|c|c|c|c|c|}
\hline Level & Parameters and Variables & Model 1 & Model 2 & Model 3 & Model 4 & Model 5 & Model 6 & Model 7 \\
\hline \multicolumn{9}{|c|}{ Fixed Effect } \\
\hline \multirow[t]{20}{*}{ Level 1} & Initial efficiency $\left(\pi_{0 \mathrm{ij}}\right)$ & & & & & & & \\
\hline & Intercept (ү000) & $\begin{array}{l}0.829^{* * *} \\
(0.017)\end{array}$ & $\begin{array}{l}0.798^{* * * *} \\
(0.021)\end{array}$ & $\begin{array}{l}0.792^{* * *} \\
(0.022)\end{array}$ & $\begin{array}{l}0.798^{* * *} \\
(0.019)\end{array}$ & $\begin{array}{l}0.843^{* * *} \\
(0.068)\end{array}$ & $\begin{array}{l}0.695^{* * *} \\
(0.092)\end{array}$ & $\begin{array}{l}0.823^{* * *} \\
(0.061)\end{array}$ \\
\hline & Linear growth rate $\left(T, \pi_{1} \mathrm{ij}\right)$ & & & & & & & \\
\hline & Intercept $\left(\beta_{100}\right)$ & & $\begin{array}{l}0.016^{* *} \\
(0.005)\end{array}$ & $\begin{array}{l}0.028^{*} \\
(0.011)\end{array}$ & & & & \\
\hline & Nonlinear growth rate $\left(T 2, \pi_{2 i j}\right)$ & & & $\begin{array}{l}-0.003 \\
(0.003)\end{array}$ & & & & \\
\hline & Intercept $\left(\beta_{200}\right)$ & & & & & & & \\
\hline & $\mathrm{FP}\left(\pi_{2 i j}\right)$ & & & & & & $\begin{array}{l}0.337^{* *} \\
(0.103)\end{array}$ & $\begin{array}{l}0.324^{* *} \\
(0.099)\end{array}$ \\
\hline & A2 $\left(\pi_{3 i j}\right)$ & & & & & & $\begin{array}{l}0.000^{* * *} \\
(0.000)\end{array}$ & $\begin{array}{l}0.000 \\
(0.000)\end{array}$ \\
\hline & $\mathrm{A} 3\left(\pi_{4 i j}\right)$ & & & & & & $\begin{array}{l}0.000 \\
(0.001)\end{array}$ & $\begin{array}{l}0.000 \\
(0.001)\end{array}$ \\
\hline & A6 $\left(\pi_{5 i j}\right)$ & & & & & & $\begin{array}{l}-0.001 \\
(0.003)\end{array}$ & $\begin{array}{l}-0.006^{*} \\
(0.002)\end{array}$ \\
\hline & $\mathrm{A} 11\left(\pi_{6 i j}\right)$ & & & & & & $\begin{array}{l}0.000 \\
(0.000)\end{array}$ & $\begin{array}{l}0.000 \\
(0.000)\end{array}$ \\
\hline & $\mathrm{V} 1\left(\pi_{7 i j}\right)$ & & & & & & $\begin{array}{l}0.119^{* *} \\
(0.044)\end{array}$ & $\begin{array}{l}0.114^{* *} \\
(0.042)\end{array}$ \\
\hline & V7 $\left(\pi_{8 i j}\right)$ & & & & & & $\begin{array}{l}-12.491^{* *} \\
(4.575)\end{array}$ & $\begin{array}{l}-10.366^{*} \\
(4.555)\end{array}$ \\
\hline & V8 $\left(\pi_{9 i j}\right)$ & & & & & & $\begin{array}{l}0.038^{* *} \\
(0.014)\end{array}$ & $\begin{array}{l}0.041^{* *} \\
(0.013)\end{array}$ \\
\hline & $\operatorname{V9}\left(\pi_{10 i j}\right)$ & & & & & & $\begin{array}{l}-0.001 \\
(0.001)\end{array}$ & $\begin{array}{l}-0.001 \\
(0.001)\end{array}$ \\
\hline & $\mathrm{V} 10\left(\pi_{11 i j}\right)$ & & & & & & $\begin{array}{l}0.000 \\
(0.001)\end{array}$ & $\begin{array}{l}0.000 \\
(0.001)\end{array}$ \\
\hline & $\mathrm{T} \times \mathrm{A} 2\left(\pi_{12 i j}\right)$ & & & & & & & $\begin{array}{l}0.000 \\
(0.000)\end{array}$ \\
\hline & $\mathrm{T} \times \mathrm{A} 3\left(\pi_{13 i j}\right)$ & & & & & & & $\begin{array}{l}0.000 \\
(0.001)\end{array}$ \\
\hline & $\mathrm{T} \times \mathrm{A} 6\left(\pi_{14 i j}\right)$ & & & & & & & $\begin{array}{l}0.003^{* *} \\
(0.001)\end{array}$ \\
\hline & $\mathrm{T} \times \mathrm{A} 11\left(\pi_{15 i j}\right)$ & & & & & & & $\begin{array}{l}0.000 \\
(0.000)\end{array}$ \\
\hline \multirow[t]{4}{*}{ Level 2} & $\operatorname{GHP}\left(\beta_{01 j}\right)$ & & & & & $\begin{array}{l}-0.025 \\
(0.024)\end{array}$ & $\begin{array}{l}0.027 \\
(0.025)\end{array}$ & $\begin{array}{l}-0.042 \\
(0.024)\end{array}$ \\
\hline & $\operatorname{IHP}\left(\beta_{02 j}\right)$ & & & & & $\begin{array}{l}0.019 \\
(0.049)\end{array}$ & $\begin{array}{l}0.037 \\
(0.048)\end{array}$ & $\begin{array}{l}0.043 \\
(0.046)\end{array}$ \\
\hline & $Z Y\left(\beta_{\text {озј }}\right)$ & & & & & $\begin{array}{l}-0.079^{*} \\
(0.038)\end{array}$ & $\begin{array}{l}-0.078^{*} \\
(0.037)\end{array}$ & $\begin{array}{l}-0.063 \\
(0.035)\end{array}$ \\
\hline & $F Y\left(\beta_{04 j}\right)$ & & & & & $\begin{array}{l}0.073 \\
(0.056)\end{array}$ & $\begin{array}{l}0.097 \\
(0.055)\end{array}$ & $\begin{array}{l}0.117^{*} \\
(0.052)\end{array}$ \\
\hline \multirow[t]{4}{*}{ Level 3} & $\operatorname{GDP}\left(\gamma_{001}\right)$ & & & & $\begin{array}{l}0.000 \\
(0.000)\end{array}$ & $\begin{array}{l}0.000 \\
(0.000)\end{array}$ & $\begin{array}{l}0.003 \\
(0.003)\end{array}$ & $\begin{array}{l}0.003 \\
(0.003)\end{array}$ \\
\hline & D1 $\left(Y_{002}\right)$ & & & & $\begin{array}{l}0.003 \\
(0.021)\end{array}$ & $\begin{array}{l}0.006 \\
(0.024)\end{array}$ & $\begin{array}{l}0.001 \\
(0.025)\end{array}$ & $\begin{array}{l}0.002 \\
(0.026)\end{array}$ \\
\hline & $\mathrm{DP}\left(\mathrm{\gamma}_{003}\right)$ & & & & $\begin{array}{l}1.105 \\
(0.699)\end{array}$ & $\begin{array}{l}0.753 \\
(0.842)\end{array}$ & $\begin{array}{l}1.216 \\
(0.782)\end{array}$ & $\begin{array}{l}1.224 \\
(0.779)\end{array}$ \\
\hline & $\mathrm{HP}\left(\gamma_{004}\right)$ & & & & -0.103 & -0.050 & -0.092 & -0.105 \\
\hline
\end{tabular}


Table 5 Results of all models (Continued)

\begin{tabular}{|c|c|c|c|c|c|c|c|c|}
\hline Level & Parameters and Variables & Model 1 & Model 2 & Model 3 & Model 4 & Model 5 & Model 6 & Model 7 \\
\hline & & & & & $(0.141)$ & $(0.149)$ & $(0.129)$ & $(0.133)$ \\
\hline & $C Z\left(Y_{005}\right)$ & & & & $\begin{array}{l}-0.005 \\
(0.003)\end{array}$ & $\begin{array}{l}-0.004 \\
(0.003)\end{array}$ & $\begin{array}{l}-0.005 \\
(0.003)\end{array}$ & $\begin{array}{l}-0.005 \\
(0.003)\end{array}$ \\
\hline & $\begin{array}{l}\text { Growth rate } \\
\left(T, \pi_{o i j}\right)\end{array}$ & & & & & & & \\
\hline & Intercept $\left(\gamma_{100}\right)$ & & $\begin{array}{l}0.016^{* *} \\
(0.005)\end{array}$ & $\begin{array}{l}0.028^{*} \\
(0.011)\end{array}$ & $\begin{array}{l}0.016^{* *} \\
(0.005)\end{array}$ & $\begin{array}{l}0.020 \\
(0.190)\end{array}$ & $\begin{array}{l}0.023 \\
(0.026)\end{array}$ & $\begin{array}{l}0.025^{*} \\
(0.013)\end{array}$ \\
\hline \multirow[t]{4}{*}{ Level 2} & $\operatorname{GHP}\left(\beta_{11 j}\right)$ & & & & & $\begin{array}{l}-0.001 \\
(0.005)\end{array}$ & $\begin{array}{l}0.001 \\
(0.004)\end{array}$ & $\begin{array}{l}0.004 \\
(0.004)\end{array}$ \\
\hline & $\operatorname{IHP}\left(\beta_{11 j}\right)$ & & & & & $\begin{array}{l}0.003 \\
(0.014)\end{array}$ & $\begin{array}{l}-0.006 \\
(0.013)\end{array}$ & $\begin{array}{l}-0.009 \\
(0.013)\end{array}$ \\
\hline & $Z Y\left(\beta_{11 j}\right)$ & & & & & $\begin{array}{l}0.013 \\
(0.011)\end{array}$ & $\begin{array}{l}0.011 \\
(0.011)\end{array}$ & $\begin{array}{l}0.008 \\
(0.008)\end{array}$ \\
\hline & $\mathrm{FY}\left(\beta_{11 j}\right)$ & & & & & $\begin{array}{l}-0.019 \\
(0.015)\end{array}$ & $\begin{array}{l}-0.032 \\
(0.018)\end{array}$ & $\begin{array}{l}-0.036^{* *} \\
(0.014)\end{array}$ \\
\hline \multirow[t]{5}{*}{ Level 3} & $\operatorname{GDP}\left(\gamma_{101}\right)$ & & & & $\begin{array}{l}0.000 \\
(0.000)\end{array}$ & $\begin{array}{l}0.000 \\
(0.000)\end{array}$ & $\begin{array}{l}-0.001 \\
(0.001)\end{array}$ & $\begin{array}{l}-0.001 \\
(0.001)\end{array}$ \\
\hline & D1 $\left(\gamma_{102}\right)$ & & & & $\begin{array}{l}0.007^{*} \\
(0.003)\end{array}$ & $\begin{array}{l}0.007^{*} \\
(0.003)\end{array}$ & $\begin{array}{l}0.009^{*} \\
(0.004)\end{array}$ & $\begin{array}{l}0.009^{*} \\
(0.004)\end{array}$ \\
\hline & $\mathrm{DP}\left(\gamma_{103}\right)$ & & & & $\begin{array}{l}-0.075 \\
(0.157)\end{array}$ & $\begin{array}{l}-0.095 \\
(0.187)\end{array}$ & $\begin{array}{l}-0.332^{*} \\
(0.169)\end{array}$ & $\begin{array}{l}-0.310 \\
(0.175)\end{array}$ \\
\hline & $\operatorname{HP}\left(\gamma_{104}\right)$ & & & & $\begin{array}{l}-0.016 \\
(0.031)\end{array}$ & $\begin{array}{l}-0.013 \\
(0.034)\end{array}$ & $\begin{array}{l}0.009 \\
(0.029)\end{array}$ & $\begin{array}{l}0.007 \\
(0.029)\end{array}$ \\
\hline & $C Z\left(\gamma_{105}\right)$ & & & & $\begin{array}{l}0.000 \\
(0.001)\end{array}$ & $\begin{array}{l}0.000 \\
(0.001)\end{array}$ & $\begin{array}{l}0.001 \\
(0.001)\end{array}$ & $\begin{array}{l}0.001 \\
(0.001)\end{array}$ \\
\hline \multicolumn{9}{|c|}{ Variance Components } \\
\hline$\sigma^{2}$ & Initial efficiency & $\begin{array}{l}0.011^{* * *} \\
(0.001)\end{array}$ & $\begin{array}{l}0.008^{* * *} \\
(0.001)\end{array}$ & $\begin{array}{l}0.007^{* * *} \\
(0.000)\end{array}$ & $\begin{array}{l}0.008^{* * *} \\
(0.001)\end{array}$ & $\begin{array}{l}0.008^{* * *} \\
(0.001)\end{array}$ & $\begin{array}{l}0.007^{* * *} \\
(0.001)\end{array}$ & $\begin{array}{l}0.006^{* * *} \\
(0.001)\end{array}$ \\
\hline \multirow[t]{2}{*}{$\sigma_{r 0}^{2}$} & Initial efficiency & $\begin{array}{l}0.012^{* * *} \\
(0.002)\end{array}$ & $\begin{array}{l}0.021^{* * *} \\
(0.004)\end{array}$ & $\begin{array}{l}0.020^{* * *} \\
(0.000)\end{array}$ & $\begin{array}{l}0.021^{* * *} \\
(0.004)\end{array}$ & $\begin{array}{l}0.014^{* * *} \\
(0.003)\end{array}$ & $\begin{array}{l}0.013^{* * *} \\
(0.003)\end{array}$ & $\begin{array}{l}0.012^{* * *} \\
(0.003)\end{array}$ \\
\hline & Growth rate & & $\begin{array}{l}0.001^{* *} \\
(0.000)\end{array}$ & $\begin{array}{l}0.004 \\
(0.000)\end{array}$ & $\begin{array}{l}0.001^{* *} \\
(0.000)\end{array}$ & $\begin{array}{l}0.001 \\
(0.000)\end{array}$ & $\begin{array}{l}0.001^{*} \\
(0.000)\end{array}$ & $\begin{array}{l}0.000^{*} \\
(0.000)\end{array}$ \\
\hline \multirow[t]{2}{*}{$\sigma_{u 0}^{2}$} & Initial efficiency & $\begin{array}{l}0.002 \\
(0.002)\end{array}$ & $\begin{array}{l}0.002 \\
(0.003)\end{array}$ & $\begin{array}{l}0.003 \\
(0.003)\end{array}$ & $\begin{array}{l}0.001 \\
(0.004)\end{array}$ & $\begin{array}{l}0.002 \\
(0.003)\end{array}$ & $\begin{array}{l}0.002 \\
(0.002)\end{array}$ & $\begin{array}{l}0.003 \\
(0.003)\end{array}$ \\
\hline & Growth rate & & $\begin{array}{l}0.000^{* *} \\
(0.000)\end{array}$ & $\begin{array}{l}0.000 \\
(0.000)\end{array}$ & $\begin{array}{l}0.000 \\
(0.000)\end{array}$ & $\begin{array}{l}0.000 \\
(0.000)\end{array}$ & $\begin{array}{l}0.000 \\
(0.000)\end{array}$ & $\begin{array}{l}0.000 \\
(0.000)\end{array}$ \\
\hline \multicolumn{9}{|c|}{ Covariance } \\
\hline Level 2 & Initial efficiency and growth rate & & $\begin{array}{l}-0.003^{* *} \\
(0.001)\end{array}$ & $\begin{array}{l}-0.002 \\
(0.002)\end{array}$ & $\begin{array}{l}-0.003^{* *} \\
(0.001)\end{array}$ & $\begin{array}{l}-0.002 \\
(0.001)\end{array}$ & $\begin{array}{l}-0.001 \\
(0.001)\end{array}$ & $\begin{array}{l}-0.001 \\
(0.001)\end{array}$ \\
\hline Level 3 & & & $\begin{array}{l}0.000 \\
(0.000)\end{array}$ & $\begin{array}{l}-0.001 \\
(0.001)\end{array}$ & $\begin{array}{l}0.000 \\
(0.001)\end{array}$ & $\begin{array}{l}0.000 \\
(0.001)\end{array}$ & $\begin{array}{l}0.000 \\
(0.000)\end{array}$ & $\begin{array}{l}0.000 \\
(0.001)\end{array}$ \\
\hline \multirow[t]{4}{*}{ Model fit } & $\mathrm{Np}$ & 4 & 9 & 16 & 19 & 27 & 37 & 41 \\
\hline & $\mathrm{LL}$ & 228.239 & 247.529 & 250.324 & 251.646 & 260.718 & 292.292 & 302.857 \\
\hline & AIC & -448.490 & -477.059 & -468.649 & -465.291 & -467.436 & -510.584 & -523.713 \\
\hline & $\mathrm{BIC}$ & -432.946 & -442.084 & -406.471 & -392.455 & -362.511 & -366.798 & -364.383 \\
\hline \multirow[t]{2}{*}{ ICC } & Level 2 & 0.482 & & & & & & \\
\hline & Level 3 & 0.081 & & & & & & \\
\hline
\end{tabular}

Note: ${ }^{*} p<0.05,{ }^{* *} p<0.01$, and ${ }^{* * *} p<0.001$. Np the model estimation parameter, LL logarithmic likelihood ratio, AIC Akaike information criterion, BIC Bayesian information criterion, ICC intraclass correlation coefficient 
growth model were not significant. This suggests that the growth rate of only the linear growth model differs between hospitals and counties. In addition, judging from the model-fitting, the Akaike and Bayesian information criteria of the linear growth model were lesser than those of the nonlinear growth model, indicating that the linear growth model fitted better. Judging from the above, county public hospital efficiency exhibits linear growth, and this growth was different for different hospitals and counties. Thus, the multilevel linear growth model for the "time-hospital-county" was suitable in this context.

Adding variables in turn from level 3 to level 1 resulted in Eqs. 4, 5 and $6^{4}$ and model 7. According to the results of the full model (Eq. 7) in Table 5, FP $(\beta=$ $0.324), V 1(\beta=0.114)$, and $V 8(\beta=0.041)$ had significant, positive effects on the initial efficiency, while $A 6(\beta=-$ $0.006)$ and $V 7(\beta=-10.366)$ had significant, negative effects. In level 2, the influence of the variable GHP on the initial efficiency was not significant, and the initial efficiency of MCHHs was significantly higher than that of GHs $(\beta=0.11)$. However, there was no significant difference between the initial efficiency score of TCMHs and GHs, and no variables at level 3 had significant impacts on initial efficiency. In terms of growth rate, the efficiency growth rate of $\mathrm{MCHHs}$ at level 2 was significantly lower than that of GHs $(\beta=-0.036)$. The GHP had no significant impacts on the growth rate, and there was no significant difference in the efficiency growth rate between TCMHs and GHs. The variable D1 in level 3 had a significant, positive effect on the growth rate $\beta=$ 0.009). However, the impact of $G D P, D P, H P$, and $C Z$ on the growth rate was not significant. Results of the simultaneous interaction were shown in Table 5 and depicted a significant increase in hospital efficiency $(\beta=0.025)$; that is, an average annual increase of 0.025 . At level 1 , only the interaction of $A 6$ and $T$ were significant $(\beta=$ $0.003)$. In addition, THP $(F Y)$ and $D 1$ also had significant impacts on the growth rate. To better understand the results of the final model (Eq. 7), we showed the results graphically in Fig. 2. The graphs displayed the modelbased trajectories for $A 6, T H P$, and $D 1$, further subdivided by high and low levels, which were defined as one standard deviation (SD) above and below the mean, respectively. According to the results of Table 6, when $D 1$ and $A 6$ are high, the efficiency of the GHs increases significantly (the slope was 0.064 , with an average annual increase of 0.064). For a high $D 1$ and low $A 6$, the efficiency of the MCHHs decreased significantly (the slope was -0.049 , with an average annual decrease of 0.049 ).

\footnotetext{
${ }^{4}$ Models 3, 4, and 5 were estimated, but their results were not discussed due to space limitations.
}

\section{Discussion}

Effective health promotion measures are a crucial part of bringing the differences of efficiency in the initial efficiency and linear growth between hospitals and counties in Chongqing into parity. The results presented in section 4 provide timely implications.

\section{Inter-County level implications}

Previous studies suggest that greater competition is positively associated with efficiency [13]. However, the present study finds that HP does not affect the initial score and growth rate of hospital efficiency. Possible explanation of this result is that a county's medical market competition cannot function well as a market that allocates resources due to the existence of monopoly, externality, etc. Existing health resources of hospital are still far from meeting the service requirements. Further analysis is needed to confirm this explanation. Moreover, D1 has a significant, positive impact on the growth rate of efficiency. Combined with the theory of economies of scale, it should take into account the service radius, population density, amount of services that hospitals can actually carry, and competition between county medical institutions in expanding the resources and scale to avoid blind development. Therefore, maintaining the stability of the current number and reasonable increase in the number of new county health technicians is significant to the next reform according to model results.

Geographical locations are also significant determinants of efficiency [19], although this study illustrates that the impacts of GDP and $C Z$ on the growth rate are not significant. This is in contrast with the traditional relationship between hospital service efficiency and the level of economic development seen in the past, and it provides another perspective for future researchers other than the level of counties' economic development.

\section{Inter-hospital level implications}

This study shows that GHP has no effect on the initial efficiency and growth rate of hospital efficiency. The initial efficiency score for $\mathrm{MCHHs}$ is higher than that for $\mathrm{GHs}$, and there is no significant difference in the initial efficiency and growth rate between TCMHs and GHs. However, the growth rate of $\mathrm{MCHHs}$ is significantly lower than that of GHs. This means that, in 2012, the efficiency of MCHHs was relatively high in Chongqing, but efficiency growth between 2012 and 2016 was significantly lower for GHs and TCMHs. The reason may be that, since the new medical reform, the state has reformed GHs and TCMHs more vigorously to ensure they are fully functional and effective. Meanwhile, the construction of a traditional medicine services system has been incorporated into regional health plans. As the main entities of this system, TCMHs have increased investment in infrastructure 


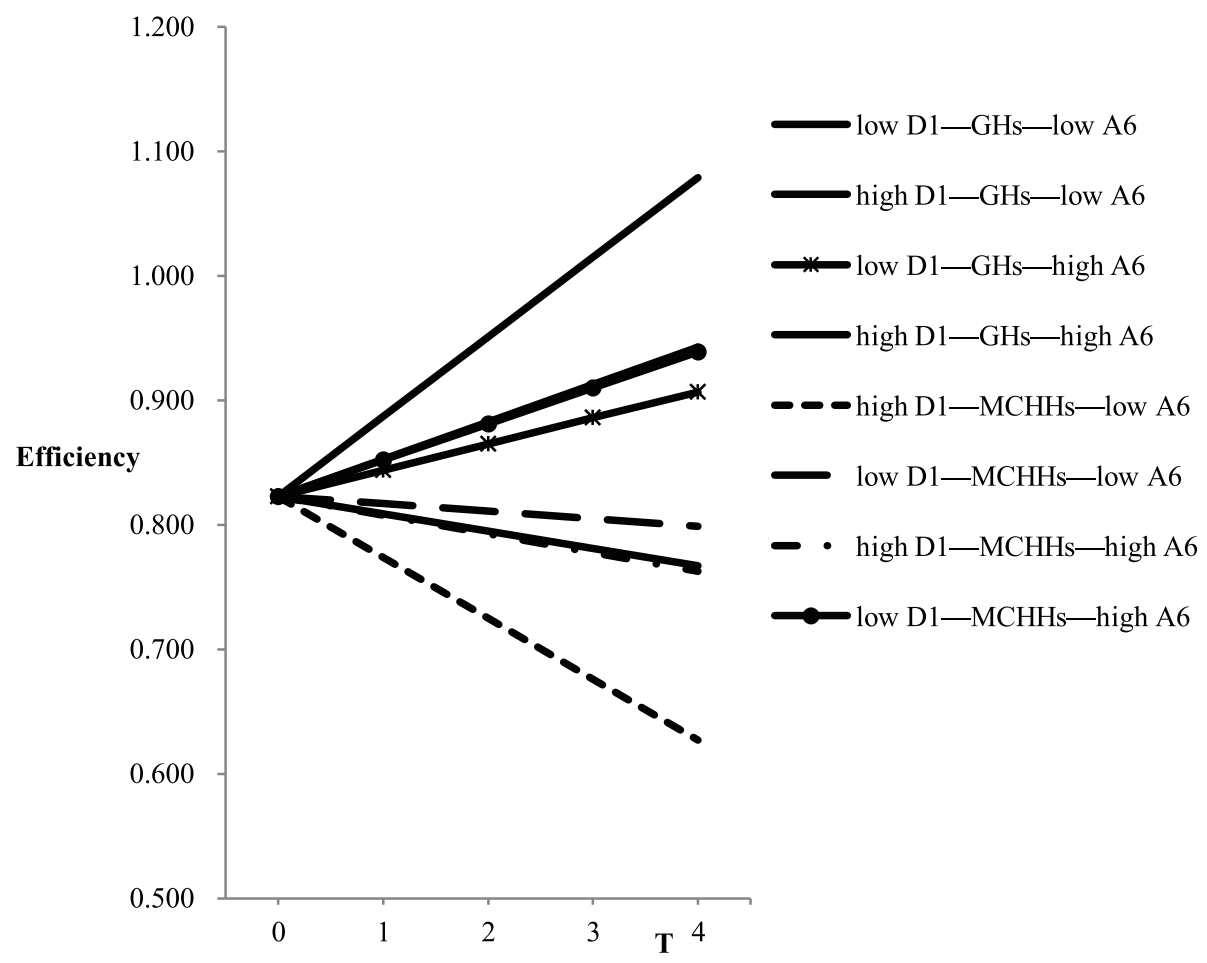

Fig. 2 Three-level interaction effects. A6 = number of healthcare technicians; D1 = number of healthcare technicians per 1000 people; GH= general hospital; $\mathrm{MCHH}=$ maternal and child healthcare hospital. The variables take "mean-1 standard deviation" as the low level and "mean+1 standard deviation" as the high level

and personnel, strengthened discipline development, vigorously promoted appropriate technologies, improved their ability to innovate in science and technology, and improved their overall efficiency. Further reform should focus on MCHHs for increasing investment and implementing government compensation.

\section{Intra-hospital level implications}

$F P$ has a positive impact on the initial efficiency of public hospitals at level 1 , which is in line with a previous study [62]. One reasonable explanation is that the General Office of the State Council issued the "Guidance on the
Comprehensive Reform of Urban Public Hospitals" on May 17, 2015 (National Office, 2015, No. 38) and proposed that the compensation channel for public hospitals should be changed from original service charges, income from the sale of drugs, and government subsidies to service charges and government subsidies. As an important source of compensation, government subsidies have a positive impact on the operation of public hospitals.

In a review of the literature on medical personnel, Tsekouras et al. [19] find that medical personnel are crucial for the improvement of public hospitals' productive efficiency. Results of the present study show that A6 has

Table 6 Simple slope of the model adjusted simultaneously

\begin{tabular}{|c|c|c|}
\hline Group & Simple slope equation & Significance of slope $(p)$ \\
\hline low D1- $\mathrm{GH}_{\mathrm{S}}-$ low A6 & $y=-0.014 T+0.823$ & 0.482 \\
\hline high D1- $\mathrm{GH}_{\mathrm{S}}$-low A6 & $y=0.030 T+0.823$ & 0.091 \\
\hline low D1- $\mathrm{GH}_{\mathrm{S}}$-high A6 & $y=0.021 T+0.823$ & 0.184 \\
\hline high D1- $\mathrm{GH}_{\mathrm{S}}-$ high A6 & $y=0.064 T+0.823$ & $0.000^{* * *}$ \\
\hline high $\mathrm{D} 1-\mathrm{MCHH}_{\mathrm{S}}-$ low A6 & $y=-0.049 T+0.823$ & $0.002^{* *}$ \\
\hline low D1- $\mathrm{MCHH}_{\mathrm{S}}$-low A6 & $y=-0.006 T+0.823$ & 0.694 \\
\hline high D1- $\mathrm{MCHH}_{\mathrm{S}}$-high A6 & $y=-0.015 T+0.823$ & 0.294 \\
\hline low D1— $\mathrm{MCHH}_{\mathrm{S}}$-high A6 & $y=0.029 T+0.823$ & 0.097 \\
\hline
\end{tabular}

Note: ${ }^{* *} p<0.01$, and ${ }^{* * *} p<0.001$. Number of healthcare technicians (A6) and number of healthcare technicians per 1000 people (D1) take "mean - 1 standard deviation" as the low level and "mean +1 standard deviation" as the high level. GHs general hospitals, MCHHs maternal and child healthcare hospitals 
a significant, negative impact on the initial efficiency. This is consistent with the information revealed by the iutput-oriented DEA model, which hints that the number of health technicians in the hospital must be reduced to be more efficient in a given output, and also match the principles of basic microeconomics.

Moreover, $V 7$ has a significant, negative effect on the initial efficiency. The "Guidance of the General Office of the State Council on the Pilot Reform of Urban Public Hospitals" (National Office, 2015, No. 38) notes that, by 2017, the consumption of health materials in $V 7$ of public hospitals in pilot cities will be reduced to less than 20 yuan. This indicator is used as a key factor in the cost control of hospitals. The control of the consumption ratio of 100yuan medical income has promoted the rationalization and adjustment of the medical income structure, optimized the level of hospitals' organizational efficiency, effectively promoted the structural adjustment of medical income, and improved hospital efficiency [63].

\section{Implications of the interaction of variables}

An important implication of the results is that $A 2, A 3$, $A 6$, and $A 11$ separately affect the relationship between $T$ and efficiency, which can significantly affect growth rates. When these four interaction items are included simultaneously, there is a significant increase in efficiency, with an average annual increase of 0.025 . However, only $D 1, T H P$, and $A 6$ remain significant, and interactions of other terms should be explored in future research with a larger sample. The stability and increase of $D 1$ in a county are factors that improve the efficiency of county-level hospitals in Chongqing.

Finally, it should be noted that the situation of countylevel public hospitals in different counties of Chongqing is more complex, and the limited factors in this model cannot fully explain the growth trajectory of hospital efficiency or the differences. The results of the analysis show that after considering the relevant factors of hospital and county characteristics, some indicators still exhibit significant differences between hospitals and counties. Some hospital-specific indicators, such as FP, $V 1$, and $V 8$, also vary between hospitals or counties. The difference is mainly reflected in the initial efficiency rather than the growth rate. That is, these differences in indicators can be explained by factors at the hospital level. In this study, the variation of hospital efficiency is decomposed into the difference among Intra-hospital, Inter-hospitals, and Inter-counties so that the random error of individuals is purer, and the obtained parameters are more accurate. The reasons for the difference in hospital efficiency can be more rationally analyzed and explained. As studies on hospital efficiency have infrequently used multilevel growth models, the results of related studies should be interpreted and treated with significant caution. The following are noteworthy limitations of this study. First, the sample size for this study is relatively insufficient, and some meaningful results have not been observed. Although, results of the study have good robustness to the change in the efficiency trend, because five rounds of panel data were selected [44]. Second, this study is limited by the variables available in the Chongqing Information Platform. Other variables not incorporated in the model include the health policy system, health service needs, responsiveness, and health status of the population, which can be collected through interviews, questionnaires, etc. The study's implications are relatively limited, which limits the pertinence and reliability of the research conclusions. Third, reform itself is really a non-ignorable factor for hospital efficiency change over time. Since it is not the focus of this paper, it is not taken into account in this research design. Discussing the impact of reform on efficiency will be a meaningful direction for future studies.

Despite these limitations, this study is a useful preliminary study, based on the existing information system platform, to explore factors over time and at different levels in Chinese county-level hospitals during the period of new healthcare reform.

\section{Conclusion}

This study describes and demonstrates the importance of examining both hospital and county characteristics related to efficiency over time. With the application of multilevel analysis techniques, the method of hospital efficiency evaluation has undergone a fundamental change. A three-level growth model describes relationships between time, hospital characteristics, and county characteristics. In this study, the variation of hospital efficiency is decomposed into different levels, which increases the purity of the random error of individuals, and the parameter estimation is more accurate. The reasons for the difference in hospital efficiency can be analyzed and explained more accurately. The results of this study illustrate that per capita GDP has no significant effect on efficiency, but government financial assistance to hospitals has a significant, positive effect. This is because counties with a developed economy can guarantee financial subsidies to hospitals. There is a possibility that a county's economy indirectly affects hospital efficiency through fiscal aid. Therefore, there is a need within this field for further studies that use a large sample. Combined with the above results, the stability and reasonable increase in the number of healthcare technicians in a county are the key factors that improve the efficiency of county-level hospitals in Chongqing. Further reform should focus on $\mathrm{MCHHs}$ for increasing investment and implementing government compensation. 


\section{Abbreviations}

DEA: Data envelopment analysis; GDP: Gross Domestic Product; GHs: General hospitals; ICC: Intraclass correlation coefficient; MCHHs: Maternal and child healthcare hospitals; SD: Standard deviation; TCMHs: Traditional Chinese medicine hospitals

\section{Acknowledgments}

We are grateful to all researchers involved in the project as well as all the experts for reviewing the manuscript.

\section{Authors' contributions}

All authors designed study and the research questions. YYC contributed to the writing - review and editing, supervision and funding acquisition. $J$ L1(Jing Liu) and GRW contributed to the writing - original draft preparation and data analysis. $\mathrm{BBH}$ contributed to the project administration. $\mathrm{XLX}, \mathrm{LMZ}$, and JL2 (Jiang Li) contributed to the data curation. All authors read, revised and approved the final manuscript.

\section{Funding}

This study was supported by The Loan Project of the International Bank for Chongqing Coordinated Urban and Rural Development and Reform Project (CURIP) Phase II Health Project(P126210). Funding body had no role in the design of the study and collection, analysis, and interpretation of data and in writing the manuscript, which is solely the work of the authors.

\section{Availability of data and materials}

All data generated or analyzed in this study are included in this published study and the additional tables. The used statistical data during this research are available on the official website of the Chongqing Health Statistics, http://tj.cqshic.com/category.aspx?id=5c4e162b-e84b-4964-9b43-83f2a38d5 sed

The datasets and materials during the current study are available from the corresponding author on reasonable request.

\section{Ethics approval and consent to participate}

Not applicable. This manuscript does not involve the use of any animal or human data or tissue.

\section{Consent for publication}

Not applicable.

\section{Competing interests}

The authors declare that they have no competing interests.

\begin{abstract}
Author details
${ }^{1}$ Key Lab of Health Technology Assessment, National Health Commission, School of Public Health, Fudan University, Shanghai 200032, People's Republic of China. ${ }^{2}$ Department of Health Management, School of Management, Hainan Medical University, Hainan 571199, People's Republic of China. ${ }^{3}$ Hospital Management Institute, Fudan University, Shanghai 200032, People's Republic of China. ${ }^{4}$ Department of Statistics and Development Research, Chongqing Health Information Center, Chongqing 401120, People's Republic of China.
\end{abstract}

\section{Received: 13 January 2019 Accepted: 3 October 2019}

Published online: 21 November 2019

\section{References}

1. Barber SL, Borowitz M, Bekedam H, Ma J. The hospital of the future in China: China's reform of public hospitals and trends from industrialized countries. Health Policy Plan. 2014;29:367-78.

2. Tucker AL, Singer SJ, Hayes JE, Falwell A. Front-line staff perspectives on opportunities for improving the safety and efficiency of hospital work systems. Health Serv Res. 2008:43:1807-29.

3. National Health Commission of the People's Republic of China. China Health Statistics Yearbook 2018. China Union Medical University Press; 2018. p. 93.

4. Fang PQ, Min R, Zou XX. Key points and pathway of county public hospital reform in China. Chin Hosp Manag. 2014;34:4-8.
5. Li NN, Wang $\mathrm{CH}, \mathrm{Ni} \mathrm{H}$, Wang $\mathrm{H}$. Efficiency and productivity of county-level public hospitals based on the data envelopment analysis model and Malmquist index in Anhui. China Chin Med J. 2017;130:2836-43.

6. Cheng ZH, Tao HB, Cai M, Lin HF, Lin XJ, Shu Q, et al. Using a two-stage data envelopment analysis to estimate the efficiency of county hospitals in China: a panel data study. Lancet. 2015;386(Suppl 1):64.

7. Jacobs R, Smith P, Street A. Measuring efficiency in health care: analytic techniques and health policy. Cambridge: Cambridge University Press; 2006.

8. Cantor VJM, Poh KL. Integrated analysis of healthcare efficiency: a systematic review. J Med Syst. 2018:42:8

9. Chongqing Municipal People's Government: City Profile. http://www.cq.gov. cn/zqfz/zhsq/sqij. Accessed 20 Feb 2018.

10. Sun J, Luo H. Evaluation on equality and efficiency of health resources allocation and health services utilization in China. Int J Equity Health. 2017; 16:127.

11. Hollingsworth B, Wildman J. The efficiency of health production: reestimating the $\mathrm{WHO}$ panel data using parametric and non-parametric approaches to provide additional information. Health Econ. 2003;12: 493-504.

12. O'Neill L, Rauner M, Heidenberger K, Kraus M. A cross-national comparison and taxonomy of DEA-based hospital efficiency studies. Socio Econ Plan Sci. 2008:42:158-89.

13. Garcia-Lacalle J, Martin E. Rural vs urban hospital performance in a 'competitive' public health service. Soc Sci Med. 2010;71:1131-40.

14. Rosko MD, Mutter RL. What have we learned from the application of stochastic frontier analysis to U.S. hospitals? Med Care Res Rev. 2011;68: 75S-100S.

15. Magnussen J. Efficiency measurement and the operationalization of hospital production. Health Serv Res. 1996;31:21-37.

16. Grosskopf S, Margaritis D, Valdmanis VG. Competitive effects on teaching hospitals. Eur J Oper Res. 2004;154:515-25.

17. Lee KS, Chun KH, Lee JS. Reforming the hospital service structure to improve efficiency: urban hospital specialization. Health Policy. 2008;87:41-9.

18. Blank JL, Valdmanis VG. Environmental factors and productivity on Dutch hospitals: a semi-parametric approach. Health Care Manag Sci. 2010;13:27-34.

19. Tsekouras K, Papathanassopoulos F, Kounetas K, Pappous G. Does the adoption of new technology boost productive efficiency in the public sector? The case of ICUs system. Int J Prod Econ. 2010;128:427-33.

20. Nedelea IC, Fannin JM. Analyzing cost efficiency of critical access hospitals. J Policy Model. 2013;35:183-95.

21. Ding DX. The effect of experience, ownership and focus on productive efficiency: a longitudinal study of US hospitals. J Oper Manag. 2014;32:1-14.

22. Chowdhury $H$, Zelenyuk V. Performance of hospital services in Ontario: DEA with truncated regression approach. Omega. 2016;63:111-22.

23. Chilingerian JA. Evaluating physician efficiency in hospitals: a multivariate analysis of best practices. Eur J Oper Res. 1995;80:548-74.

24. Rosko MD. Cost efficiency of US hospitals: a stochastic frontier approach. Health Econ. 2001;10:539-51.

25. Staat M. Efficiency of hospitals in Germany: a DEA-bootstrap approach. Appl Econ. 2006;38:2255-63

26. Wang X, Luo H, Qin X, Feng J, Gao H, Feng Q. Evaluation of performance and impacts of maternal and child health hospital services using data envelopment analysis in Guangxi Zhuang autonomous region, China: a comparison study among poverty and non-poverty county level hospitals. Int J Equity Health. 2016:15:131.

27. Herr A, Schmitz H, Augurzky B. Profit efficiency and ownership of German hospitals. Health Econ. 2011;20:660-74.

28. Chang SJ, Hsiao HC, Huang LH, Chang H. Taiwan quality indicator project and hospital productivity growth. Omega. 2011;39:14-22.

29. Sultan WIM, Crispim J. Measuring the efficiency of Palestinian public hospitals during 2010-2015: an application of a two-stage DEA method. BMC Health Serv Res. 2018;18:381.

30. Zheng W, Sun H, Zhang P, Zhou G, Jin Q, Lu X. A four-stage DEA-based efficiency evaluation of public hospitals in China after the implementation of new medical reforms. PLoS One. 2018;13:e0203780.

31. Barros CP, Gomes de Menezes A, Peypoch N, Solonandrasana B, Vieira JC. An analysis of hospital efficiency and productivity growth using the Luenberger indicator. Health Care Manag Sci. 2008;11:373-81.

32. Fried HO, Schmidt SS, Yaisawarng S. Incorporating the operating environment into a nonparametric measure of technical efficiency. J Prod Anal. 1999;12:249-67. 
33. Harris JE. The internal organization of hospitals: some economic implications. Bell J Econ. 1977;8:467-82.

34. Burgess JF Jr, Wilson PW. Hospital ownership and technical inefficiency. Manag Sci. 1996:42:110-23.

35. Hussey PS, de Vries H, Romley J, Wang MC, Chen SS, Shekelle PG. A systematic review of health care efficiency measures. Health Serv Res. 2009; 44:784-805.

36. Gearhart R. The robustness of cross-country healthcare rankings among homogeneous OECD countries. J Appl Econ. 2016;19:113-43.

37. Hafidz F, Ensor T, Tubeuf S. Efficiency measurement in health facilities: a systematic review in low- and middle-income countries. Appl Health Econ Health Policy. 2018;16:465-80.

38. Singer JD. Using SAS PROC MIXED to fit multilevel models, hierarchica models, and individual growth models. J Educ Behav Stat. 1998;23(4): 323-55.

39. Gee KA. Multilevel growth modeling: an introductory approach to analyzing longitudinal data for evaluators. Am J Eval. 2014;35:543-61.

40. Westra D, Angeli F, Carree M, Ruwaard D. Coopetition in health care: a multi-level analysis of its individual and organizational determinants. Soc Sci Med. 2017;186:43-51.

41. Mroczek DK, Spiro A III. Change in life satisfaction during adulthood: findings from the veterans affairs normative aging study. J Pers Soc Psychol. 2005:88:189-202

42. Taylor IM, Ntoumanis N, Standage M, Spray CM. Motivational predictors of physical education students' effort, exercise intentions, and leisure-time physical activity: a multilevel linear growth analysis. J Sport \& Exerc Psychol. 2010;32(1):99-120

43. Heck RH, Thomas SL. An introduction to multilevel modeling techniques. 2nd ed. London: Psychology Press; 2008. p. 163-200.

44. Zheng WE. Review of the application of multi-level linear model in panel research. Manag Sci. 2011;24:111-20.

45. Bliese PD, Chan D, Ployhart RE. Multilevel methods: future directions in measurement, longitudinal analyses, and nonnormal outcomes. Organ Res Methods. 2007;10:551-63.

46. Lee CY, Johnson AL. Two-dimensional efficiency decomposition to measure the demand effect in productivity analysis. Eur J Oper Res. 2012;216:584-93.

47. Cheng Z, Tao H, Cai M, Lin H, Lin X, Shu Q, et al. Technical efficiency and productivity of Chinese county hospitals: an exploratory study in Henan province. China BMJ Open. 2015;5:e007267.

48. Worthington AC. Frontier efficiency measurement in health care: a review of empirical techniques and selected applications. Med Care Res Rev. 2004;61: 135-70.

49. Kirigia JM, Asbu EZ. Technical and scale efficiency of public community hospitals in Eritrea: an exploratory study. Health Econ Rev. 2013:3:6.

50. Afonso A, St. Aubyn M. Assessing health efficiency across countries with a two-step and bootstrap analysis. Appl Econ Lett. 2011:18:1427-30.

51. Rahman MA, Capitman JA. Factors affecting profit efficiency of private hospitals in Bangladesh: are urban hospitals more profit-efficient? J Health Manag. 2012;14:83-96

52. Ng YC. The productive efficiency of Chinese hospitals. China Econ Rev. 2011;22:428-39

53. Li H, Dong S, Liu T. Relative efficiency and productivity: a preliminary exploration of public hospitals in Beijing China. BMC Health Serv Res. 2014; 14:158.

54. Ozcan YA, Luke RD. A national study of the efficiency of hospitals in urban markets. Health Serv Res. 1993;27:719-39.

55. Sherman HD. Hospital efficiency measurement and evaluation: empirica test of a new technique. Med Care. 1984;22:922-38.

56. Wang Y. Efficiency evaluation of medical Services in Shandong County Public Hospitals. Shandong University 2015.

57. Zhang XN. Analysis on the effect of comprehensive reform of county-level public hospitals in Jiangsu Province. Nanjing University of Chinese Medicine2018.

58. Chen JX. Trial reform of public hospitals at the county level in Fujian province efficiency analysis-based on empirical analysis of the DEA model. Tianjin Medical University2016.

59. Zhang XH. Study on efficiency for medical resources allocation of Ningxia County public hospital. Ningxia Medical University 2016.

60. Cohen J. Statistical power and analysis for the behavioral sciences. New York: Academic Press; 1997. p. 456-67.
61. Snijders TAB, Bosker R. Modeled variance in two-level models. Sociol Methods Res. 1994:22:342-63.

62. Yang SX, Dai T, Ju H. The impact of financial subsidy of economic operation of county-level hospitals: empirical analysis based on pilot counties. Chin Health Econ. 2016;35:10-3.

63. Wen SD, Jiang Z, Li Z, Zhang T, Fan C, Jiang B. Application practice on the consumable proportion of target examination's medical income costed above 100 Yuan. Chin Health Econ. 2017;36:83-4.

\section{Publisher's Note}

Springer Nature remains neutral with regard to jurisdictional claims in published maps and institutional affiliations.
Ready to submit your research? Choose BMC and benefit from:

- fast, convenient online submission

- thorough peer review by experienced researchers in your field

- rapid publication on acceptance

- support for research data, including large and complex data types

- gold Open Access which fosters wider collaboration and increased citations

- maximum visibility for your research: over $100 \mathrm{M}$ website views per year

At BMC, research is always in progress.

Learn more biomedcentral.com/submissions 